\title{
CITED1 gene promotes proliferation, migration and invasion in papillary thyroid cancer
}

\author{
ERJIE XIA* , YINGHAO WANG* , ADHEESH BHANDARI, JIZHAO NIU, \\ FAN YANG, ZHIHAN YAO and OUCHEN WANG \\ Department of Surgical Oncology, The First Affiliated Hospital of Wenzhou Medical University, \\ Wenzhou, Zhejiang 325000, P.R. China
}

Received September 22, 2017; Accepted January 22, 2018

DOI: $10.3892 / \mathrm{ol} .2018 .8653$

\begin{abstract}
Thyroid cancer is the most common malignancy of the endocrine organs. In order to further understand the tumorigenesis and progression of papillary thyroid carcinoma (PTC), the present study performed whole transcriptome sequence analysis. It was found that $\mathrm{Cbp} / \mathrm{p} 300$-interacting transactivators with glutamic acid [E] and aspartic acid [D]-rich C-terminal domain 1 (CITED1) was a novel potential PTC-associated gene in thyroid cancer. The expression level and clinicopathological features of CITED1 were then assessed in The Cancer Genome Atlas (TCGA) database. The expression of CITED1 was knocked down and the biological function of CITED1 in PTC cell lines was examined. The results showed that upregulated CITED1 was associated with lymph node metastasis $(\mathrm{P}=0.006)$ and clinical stage $(\mathrm{P}=0.003)$. In order to differentiate PTC tissues and normal tissues, an area under the curve was constructed of a receiver operating characteristic of $91.3 \%$ for the TCGA cohort and $85.3 \%$ for a validated cohort. The downregulated expression of CITED1 significantly inhibited cell proliferation, colony formation, migration and invasion in the PTC cell lines. The present study demonstrated that CITED1 is important in the tumorigenesis and metastasis of PTC and may be a potential therapeutic target in PTC.
\end{abstract}

\section{Introduction}

Thyroid cancer is the most common malignancy of the endocrine organs. The incidence of thyroid cancer is increasing,

Correspondence to: Dr Ouchen Wang, Department of Surgical Oncology, The First Affiliated Hospital of Wenzhou Medical University, 1 New Medical Street, Nanbai Xiang, Ouhai, Wenzhou, Zhejiang 325000, P.R. China

E-mail: woconcology2000@163.com

*Contributed equally

Key words: papillary thyroid carcinoma, gene, Cbp/p300-interacting transactivator with glutamic acid and aspartic acid rich $\mathrm{C}$-terminal domain 1 having increased more than three-fold during the last three decades (1), mainly as a result of the widespread use of diagnostic imaging and surveillance. At present, in women in the USA, thyroid cancer is the fifth most common type of cancer. In 2015, there were 62,000 new cases in women and men (2). Papillary thyroid carcinoma (PTC) is the most common histological type of thyroid cancer, which is more common than other types, including follicular carcinoma, medullary carcinoma, poorly differentiated carcinoma and anaplastic carcinoma. Different types of thyroid cancer exhibit different clinical behaviors from indolent tumors, with low mortality rates in the majority of cases to aggressive malignancies, for example, anaplastic thyroid cancer. Therefore, a proper and accurate diagnosis is critical to provide an appropriate treatment approach (3).

In order to provide accurate diagnoses and personalized treatment, it is important to understand the molecular mechanisms underlying thyroid cancer occurrence and progression (4). As next generation sequence (NGS) has developed, numerous studies have examined the mechanism of thyroid cancer using NGS. There are several characteristic genetic alterations, including point mutations in proto-oncogenes (BRAF, NRAS, HRAS and KRAS) and chromosomal rearrangements (RET/PTC1, RET/PTC3 and PAX8/PPARG), which vary with histologic subtype (5).

Despite substantial progress in genetic research, the molecular mechanism of PTC remains to be fully elucidated. In order to further understand the occurrence and progression of PTC, the present study performed whole transcriptome sequencing of 19 pairs of primary thyroid cancer samples with matched adjacent normal thyroid tissues (6). Subsequently, by application of bioinformatics, it was found that upregulated $\mathrm{Cbp} / \mathrm{p} 300$-interacting transactivators with glutamic acid [E] and aspartic acid [D]-rich C-terminal domain 1 (CITED1) may be a potential gene associated with PTC.

It is well known that several genes are significantly overexpressed in PTC, which are potential markers in molecular diagnosis (7-9). However, the mechanism involved in the overexpression of these genes remains to be fully elucidated. CITED1 is one of these genes $(10,11)$. The CITED1 family of transcriptional cofactors consists of four members, which regulate diverse $\mathrm{CBP} / \mathrm{p} 300$-dependent transcriptional responses (12-14). In adults, the expression of CITED1 is 
upregulated in PTC $(11,15)$, malignant melanoma $(16,17)$, and Wilms tumor (18), which indicates that CITED1 may effectively induce tumorigenesis and progression. Other studies have found that there is a possible link between the BRAF mutation and upregulated CITED1; however, knockdown of the expression of BRAF by small interfering (si)RNA in a cell line with the BRAF V600E mutation did not induce the suppression of CITED1 $(7,19)$. Therefore, the biological function and mechanism of CITED1 in PTC remain to be elucidated.

Although studies have demonstrated that the expression level of CITED1 is associated with tumorigenesis, the biological function of CITED1 in PTC has not been examined. In the present study, transcriptome sequence analysis showed that the CITED1 gene may be significantly involved in PTC. The present study aimed to investigate the association between the expression of CITED1 and clinicopathological features, and examine the biological function of CITED1 in PTC cell lines.

\section{Materials and methods}

Patients and tissue collection. Fresh PTC tissue samples with adjacent normal thyroid tissue samples were obtained from patients with PTC at the First Affiliated Hospital of Wenzhou Medical University (Wenzhou, China) between September 2015 and September 2016. A total of 47 pairs of fresh PTC tissues with normal tissues were frozen in liquid nitrogen until further use. All tumor tissues were histologically reviewed by two pathologists. Patients signed informed consent and study protocols for the use of human tissues were approved by and performed in accordance with the ethical standards of the Ethics Committee of the First Affiliated Hospital of Wenzhou Medical University. The CITED1 Reads Per Kilobase per Million reads (RPKM) expression value was obtained via The Caner Genome Atlas (TCGA) portal (https://cancergenome.nih.gov/). In total, 375 PTC sequence data with complete clinical features and 58 pairs of thyroid cancer with matched normal tissues were selected.

Cell lines and cell culture. The human thyroid cancer cell lines (TPC1 and BCPAP) were provided by Professor Mingzhao Xing of Johns Hopkins University School of Medicine (Baltimore, MA, USA). The TPC1 and BCPAP cell lines were cultured in RPMI 1640 (Invitrogen; Thermo Fisher Scientific, Inc., Waltham, MA, USA) supplemented with $10 \%$ fetal bovine serum (FBS; Invitrogen; Thermo Fisher Scientific, Inc.), 1X MEM nonessential amino acids and $1 \mathrm{X}$ sodium pyruvate. All cells were maintained in a humidified incubator at $37^{\circ} \mathrm{C}$ with $5 \% \mathrm{CO}_{2}$.

RNA isolation and reverse transcription-quantitative polymerase chain reaction ( $R T-q P C R)$ analysis. Total RNA was isolated from the tissues or cell lines using TRIzol ${ }^{\circledR}$ reagent (Invitrogen; Thermo Fisher Scientific, Inc.) according to manufacturer's protocol. Reverse transcription was performed with ReverTra Ace ${ }^{\circledR}$ qPCR RT Kit (Toyobo Co., Ltd., Osaka, Japan) according to the manufacturer's protocol (20 $\mu \mathrm{l}$ reaction: $14 \mu \mathrm{l}$ RNA+ $4 \mu 1$ 5xRT Buffer+ $1 \mu 1$ Primer Mix $+1 \mu 1$ EnzymeMix, step $116^{\circ} \mathrm{C}$ for $5 \mathrm{~min}$, step $242^{\circ} \mathrm{C}$ for $30 \mathrm{~min}$, step $398^{\circ} \mathrm{C}$ for $5 \mathrm{~min}$ ). The RT-qPCR analysis was performed using the Applied Biosystems QuantStudio 5 Real-Time PCR system (Applied Biosystems; Thermo Fisher Scientific, Inc.) with THUNDERBIRD SYBR qPCR mix (Toyobo Co., Ltd.) according to the manufacturer's protocol (20 $\mu \mathrm{l}$ reaction: $1 \mu \mathrm{l}$ cDNA+ $7 \mu$ l RNA-free water+ $0.8 \mu$ l forward primer+ $0.8 \mu \mathrm{l}$ reverse primer+ $0.4 \mu \mathrm{l}$ ROX+ $10 \mu 1$ Thunderbird SYBR qPCR Mix, the concentration of primer was $0.2 \mu \mathrm{M}$, step $195^{\circ} \mathrm{C}$ for $2 \mathrm{~min}$, step $295^{\circ} \mathrm{C}$ for $15 \mathrm{sec}$, step $360^{\circ} \mathrm{C}$ for $60 \mathrm{sec}$, repeat step 2 and step 3 for 40 cycles, final step $72^{\circ} \mathrm{C}$ for $5 \mathrm{~min}$ ). GAPDH was used as internal control. The relative expression levels were calculated using the $2^{-\Delta \Delta C q}$ equation (20). The primer sequences for PCR were as follows: CITED1, forward 5'-AGGATGCCAACCAAGAGATG-3' and reverse 5'-GTTTAGTGGGAGGGGTGGTT-3'; GAPDH, forward 5'-GGTCGGAGTCAACGGATTTG-3' and reverse 5'-ATG AGCCCCAGCCTTCTCCAT-3'.

Transfection. A siRNA against CITED1 was purchased from Shanghai Gene Pharma (Shanghai, China). The TPC1 $\left(6 \times 10^{4}\right.$ cells $)$ and BCPAP $\left(12 \times 10^{8}\right.$ cells $)$ cell lines were inoculated in 6-well plates $24 \mathrm{~h}$ prior to transfection to achieve $50 \%$ confluence. RNAiMAX (Thermo Fisher Scientific, Inc.) was used to transfect cells with the constructs. After $24 \mathrm{~h}$, the cells were harvested, and the knockdown efficiency was verified using RT-qPCR analysis. The siRNA sequences were as follows: siRNA1, forward 5'-GGCCUGCACUUGAUG UCAATT-3' and reverse 5'-UUGACAUCAAGUGCAGGC CTT-3'; siRNA2, forward 5'-GAGCCCUGCUAUCAUCGA UTT-3' and reverse 5'-AUCGAUGAUAGCAGGGCUCTT-3'; siRNA3, forward 5'-GGGAUCUCCAAUAGGCUCUTT-3' and reverse 5'-AGAGCCUAUUGGAGAUCCCTT-3'. All assays were performed in triplicate.

Cell proliferation assay. The thyroid cancer TPC1 $\left(2 \times 10^{3}\right.$ cells $)$ and BCPAP cells $\left(3 \times 10^{3}\right.$ cells) were plated into a 96-well plate and then transfected with siRNA. The plates were harvested daily. A total of $20 \mu \mathrm{l}$ MTS (Solution Cell Proliferation Assay; Promega, Fitchburg, WI, USA) was added to each well with $100 \mu \mathrm{l}$ aforementioned medium and the plate was placed at room temperature for $2 \mathrm{~h}$. The absorbance was read at $490 \mathrm{~nm}$ using a Spectramax M5 microplate reader (Molecular Devices, Sunnyvale, CA, USA). All assays were performed in triplicate.

Colony formation assay. At $48 \mathrm{~h}$ post-transfection, the two transfected cell lines or control cells $\left(2 \times 10^{3}\right.$ cells for TPC 1 and $4 \times 10^{3}$ cells for BCPAP) were initially seeded into each well of a six-well plate, and maintained in medium containing $10 \%$ FBS, which was refreshed every 2 days. Following incubation of the cells for 10 days at $37^{\circ} \mathrm{C}$ in $5 \% \mathrm{CO}_{2}$, their colonies were visible to the naked eye. The cells were fixed with $4 \%$ paraformaldehyde (PFA; Sigma; Merck Millipore, Darmstadt, Germany) for $30 \mathrm{~min}$ and stained with $0.01 \%$ crystal violet for $30 \mathrm{~min}$. The colony numbers were counted using ImageJ 1.5 software (National Institutes of Health, Bethesda, MD, USA). All assays were performed in triplicate.

Migration and invasion assays. The migration and invasion assays were performed using Transwell chambers with membranes (Corning, Inc., Corning, NY, USA). The membranes were uncoated for the migration assays and were coated with $25 \mu$ g Matrigel $^{\circledR}$ (BD Biosciences, Franklin Lakes, NJ, USA) 

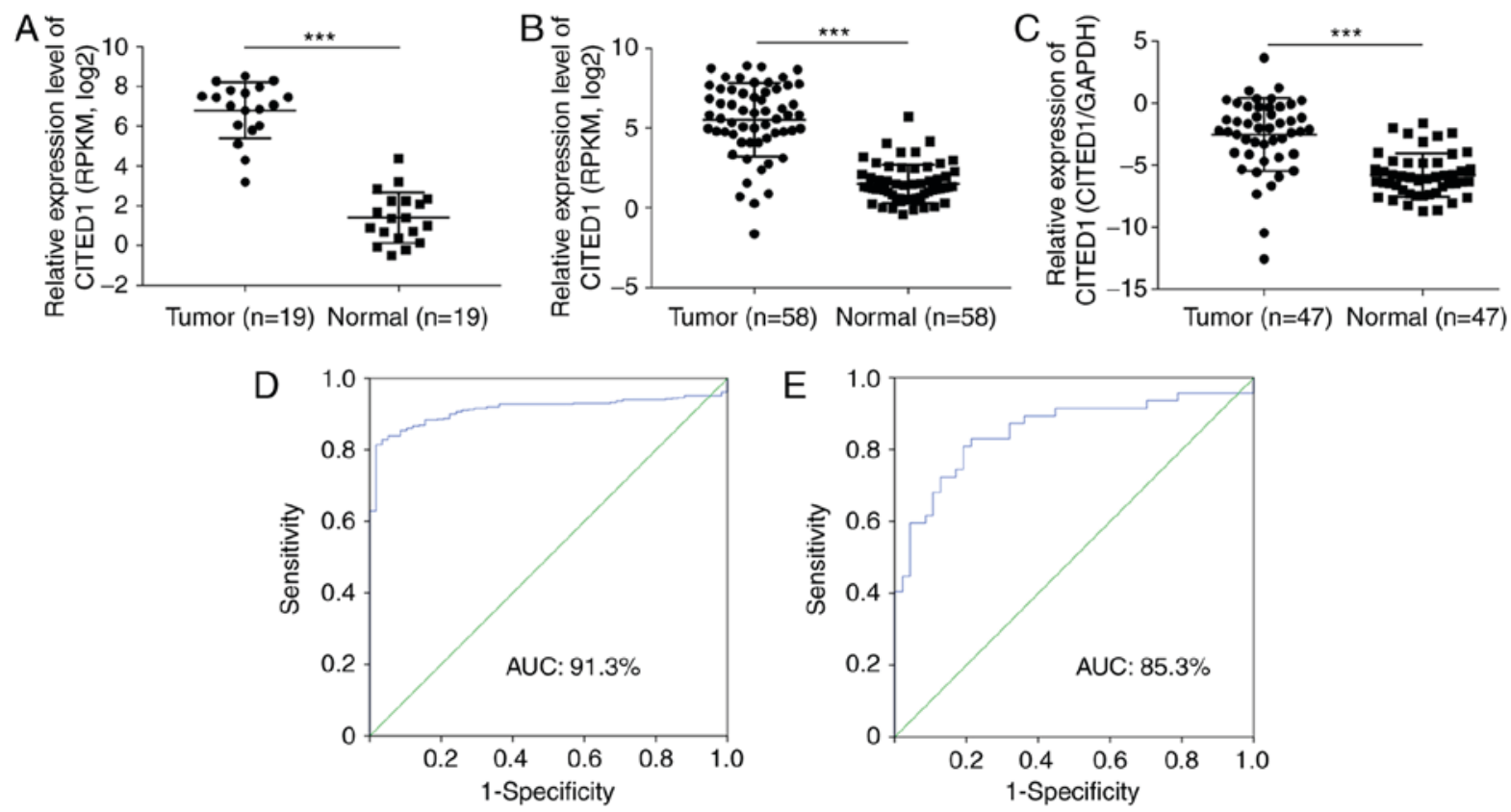

Figure 1. CITED1 expression of sequence datasets, TCGA cohort and validated cohort in thyroid cancer. (A) Sequence datasets contained 19 tumor tissues and matched adjacent normal thyroid tissues. (B) TCGA cohort contained 58 tumor tissues and matched adjacent normal thyroid tissues. RPKM was represented by the expression of UNC5B-as1. (C) Expression of CITED1 of the validated cohort, 47 tumor tissues and matched adjacent normal thyroid tissues by reverse transcription-quantitative polymerase chain reaction analysis. (D) ROC curve for expression of CITED1 to diagnose PTC in TCGA cohort. The AUC was 91.3\%, with $81.5 \%$ sensitivity and $98.3 \%$ specificity. (E) ROC curve for expression of CITED1 to diagnose PTC in the validated cohort. The AUC was $85.3 \%$, with $80.9 \%$ sensitivity and $80.9 \%$ specificity. Data are presented as the mean \pm standard deviation ranges of UNC5B-as 1 expression. ${ }^{* * *} \mathrm{P}<0.001$, compared with the normal control group using Student's t-test. PTC, papillary thyroid carcinoma; CITED1, Cbp/p300-interacting transactivators with glutamic acid [E] and aspartic acid [D]-rich C-terminal domain 1; RPKM, Reads Per Kilobase per Million reads; TGCA, The Cancer Genome Atlas; ROC, receiver operating characteristic; AUC, area under the curve.

for the invasion assays. The membranes were incubated with PBS (migration) or Matrigel ${ }^{\circledR}$ for $4 \mathrm{~h}$ at $37^{\circ} \mathrm{C}$ in a $5 \% \mathrm{CO}_{2}$ atmosphere. The transfected cells and control cells (migration assays: $3 \times 10^{4}$ cells for TPC1 and $5 \times 10^{4}$ for BCPAP; invasion assays: $6 \times 10^{4}$ cells for TPC1, 8x10 4 cells for BCPAP) were suspended in culture medium containing 5\% FBS and plated in the upper chamber; the lower chamber contained culture medium with $10 \% \mathrm{FBS}$. After $24 \mathrm{~h}$ at $37^{\circ} \mathrm{C}$ in $5 \% \mathrm{CO}_{2}$, the non-migrating cells on the top chamber were removed using a cotton swab, and those cells that migrated through the membrane were fixed (4\% PFA in PBS) and stained with $0.5 \%$ crystal violet. Images of the cells were captured using a light microscope.

Statistical analysis. Data are presented as the mean \pm standard deviation. Student's t-test (unpaired) was used to compare two groups. Two-way analysis of variance were used with an LSD post hoc test to identify significant differences among multiple groups. Categorical variables are expressed as a percentage and were compared with a $\chi^{2}$ test or Fisher's exact test, as appropriate. $\mathrm{P}<0.05$ was considered to indicate a statistically significant difference. Statistical analysis was performed with SPSS software version 22.0 (IBM SPSS, Armonk, NY, USA). GraphPad Prism 5 (GraphPad Software, Inc., La Jolla, CA, USA) was used for graphs.

\section{Results}

CITED1 is upregulated in PTC. In order to assess the results from the whole transcriptome sequence analysis
(Fig. 1A, P<0.001), the mRNA expression of CITED1 in 58 pairs of thyroid cancer with matched normal thyroid tissues was analyzed in TCGA and it was found that CITED1 was significantly upregulated in the PTC tissues, compared with that in the normal thyroid tissues (Fig. $1 \mathrm{~B}, \mathrm{P}<0.001$ ). Using RT-qPCR analysis, the mRNA expression of CITED1 was then evaluated among 47 pairs of PTC samples with matched adjacent normal thyroid tissues. The expression of CITED1 was significantly upregulated in the tumor samples, compared with that in the normal tissues (Fig. 1C, P<0.001), which was in accordance with the transcriptome sequence and TCGA datasets. In addition, receiver operating characteristic analysis was used to assess the potential diagnostic value of CITED1. For the TCGA cohort, the expression of CITED1 to distinguish thyroid cancer tissues from normal tissues had an area under the curve (AUC) value of 0.913 with a sensitivity/specificity of $81.5 / 98.3 \%$ (Fig. 1D). For the validated cohort, CITED1 identified thyroid cancer with an AUC value of 0.853 , a sensitivity of $80.9 \%$, and a specificity of $80.9 \%$ (Fig. 1E).

Association between the expression of CITEDI and clinicopathological features. To investigate the role of CITED1 in the tumorigenesis and progression in PTC, the present study analyzed the association between the expression of CITED1 and clinicopathological features. The PTC patient group was divided into two groups by the expression of CITED1, based on the median value, as a low expression group and high expression group. In the TCGA cohort, there was a significant association between a high expression of CITED1 and lymph 
Table I. Association between the expression of CITED1 and clinicopathological features in The Cancer Genome Atlas cohort.

\begin{tabular}{|c|c|c|c|}
\hline $\begin{array}{l}\text { Clinicopathological } \\
\text { features }\end{array}$ & $\begin{array}{c}\text { Low CITED1 } \\
\text { expression }(n=187), \\
n(\%)\end{array}$ & $\begin{array}{c}\text { High CITED1 } \\
\text { expression }(n=188), \\
n(\%)\end{array}$ & P-value \\
\hline Age (years) & & & 0.214 \\
\hline Mean \pm SD & $45.5 \pm 15.4$ & $47.5 \pm 15.3$ & \\
\hline$\leq 45$ & $94(50.3)$ & $82(43.6)$ & \\
\hline$>45$ & $93(49.7)$ & $106(56.4)$ & \\
\hline Gender & & & 0.228 \\
\hline Male & $54(28.9)$ & $44(23.4)$ & \\
\hline Female & $133(71.1)$ & $144(76.6)$ & \\
\hline Tumor size (cm) & & & 0.835 \\
\hline Mean & $3.03 \pm 1.77$ & $2.79 \pm 1.64$ & \\
\hline$\leq 1$ & $15(8.0)$ & $14(7.4)$ & \\
\hline$>1$ & $172(92.0)$ & $174(92.6)$ & \\
\hline Lymph node metastasis & & & 0.006 \\
\hline No & $95(50.8)$ & $69(36.7)$ & \\
\hline Yes & $92(49.2)$ & $119(63.3)$ & \\
\hline Clinical stage & & & 0.003 \\
\hline $\mathrm{I}+\mathrm{II}$ & $131(70.1)$ & $104(55.3)$ & \\
\hline III+IV & $56(29.9)$ & $84(44.7)$ & \\
\hline Histological type & & & 0.935 \\
\hline Classical & $134(71.7)$ & $134(71.3)$ & \\
\hline Other & $53(28.3)$ & $54(28.7)$ & \\
\hline
\end{tabular}

CITED1, Cbp/p300-interacting transactivators with glutamic acid [E] and aspartic acid [D]-rich C-terminal domain 1; SD, standard deviation.

Table II. Univariate logistic regression analysis for the risk of lymph node metastasis.

\begin{tabular}{|c|c|c|c|}
\hline Factor & OR & $95 \% \mathrm{CI}$ & P-value \\
\hline $\begin{array}{l}\text { CITED1 expression } \\
\text { (high, vs. low) }\end{array}$ & 1.781 & $1.179-2.69$ & 0.006 \\
\hline Age, years $(\leq 45$ vs. $>45)$ & 0.646 & $0.428-0.976$ & 0.038 \\
\hline Gender (male vs. female) & 0.501 & $0.308-0.815$ & 0.005 \\
\hline Histological type & 0.358 & $0.226-0.569$ & $<0.001$ \\
\hline Tumor size (cm) & 2.242 & $1.028-4.889$ & 0.042 \\
\hline
\end{tabular}

CITED1, Cbp/p300-interacting transactivators with glutamic acid [E] and aspartic acid [D]-rich C-terminal domain 1.

node metastasis $(\mathrm{P}=0.006)$ and clinical stage $(\mathrm{P}=0.003)$, as shown in Table I. However, the expression of CITED1 was not associated with age $(\mathrm{P}=0.214)$, gender $(\mathrm{P}=228)$, tumor size $(\mathrm{P}=0.835)$ or histological type $(\mathrm{P}=0.935)$ in either cohort $(\mathrm{P}>0.05)$.

Upregulated expression of CITEDI increases the risk of lymph node metastasis in patients with PTC. In order to investigate whether the expression of CITED1 is a major risk factor for lymph node metastasis, logistic regression
Table III. Multivariate logistic regression analysis for risk of lymph node metastasis.

\begin{tabular}{lccr}
\hline Factor & OR & $95 \%$ CI & P-value \\
\hline $\begin{array}{l}\text { CITED1 expression } \\
\text { (high, vs. low) }\end{array}$ & 2.007 & $1.295-3.109$ & 0.002 \\
Age ( $\leq 45$ vs. $>45)$ & 0.639 & $0.412-0.989$ & 0.045 \\
Gender (male vs. female) & 0.473 & $0.284-0.786$ & 0.004 \\
Histological type & 0.371 & $0.229-0.600$ & $<0.001$ \\
Tumor size (cm) & 2.171 & $0.962-4.900$ & 0.062 \\
\hline
\end{tabular}

CITED1, Cbp/p300-interacting transactivators with glutamic acid [E] and aspartic acid [D]-rich C-terminal domain 1.

was performed. Univariate logistic regression analysis demonstrated that the significant variables for lymph node metastasis were expression of CITED1 (OR 1.781, 95\% CI 1.179-2.69, $\mathrm{P}=0.006)$, age (OR 0.646, 95\% CI 0.428-0.976, $\mathrm{P}=0.038)$, gender (OR 0.501, 95\% CI 0.308-0.815, $\mathrm{P}=0.005$ ), histological type (OR 0.358, 95\% CI 0.226-0.569, $\mathrm{P}<0.001$ ) and tumor size (OR 2.242, 95\% CI 1.028-4.889, $\mathrm{P}=0.042$ ), as shown in Table II. Multivariate logistic analysis also showed that the expression of CITED1 (OR 2.007, 95\% CI 1.295-3.109, $\mathrm{P}=0.002)$, age (OR 0.639, 95\% CI 0.412-0.989, $\mathrm{P}=0.045$ ), 


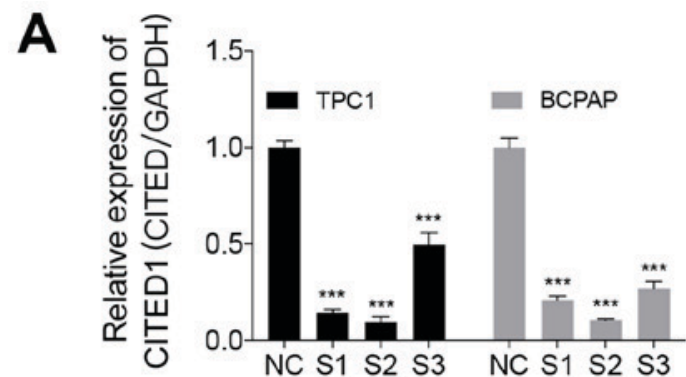

B

\section{TPC1}
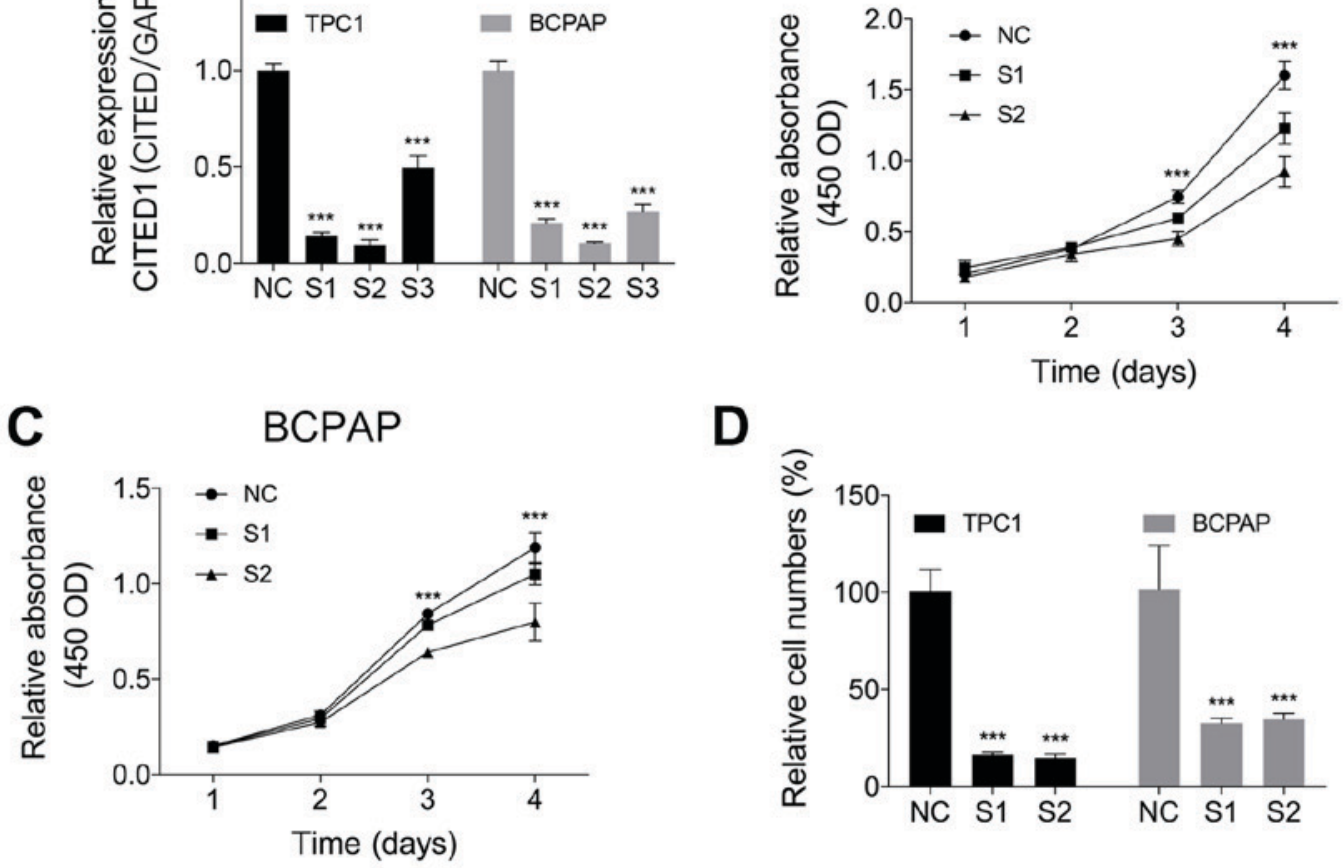

D
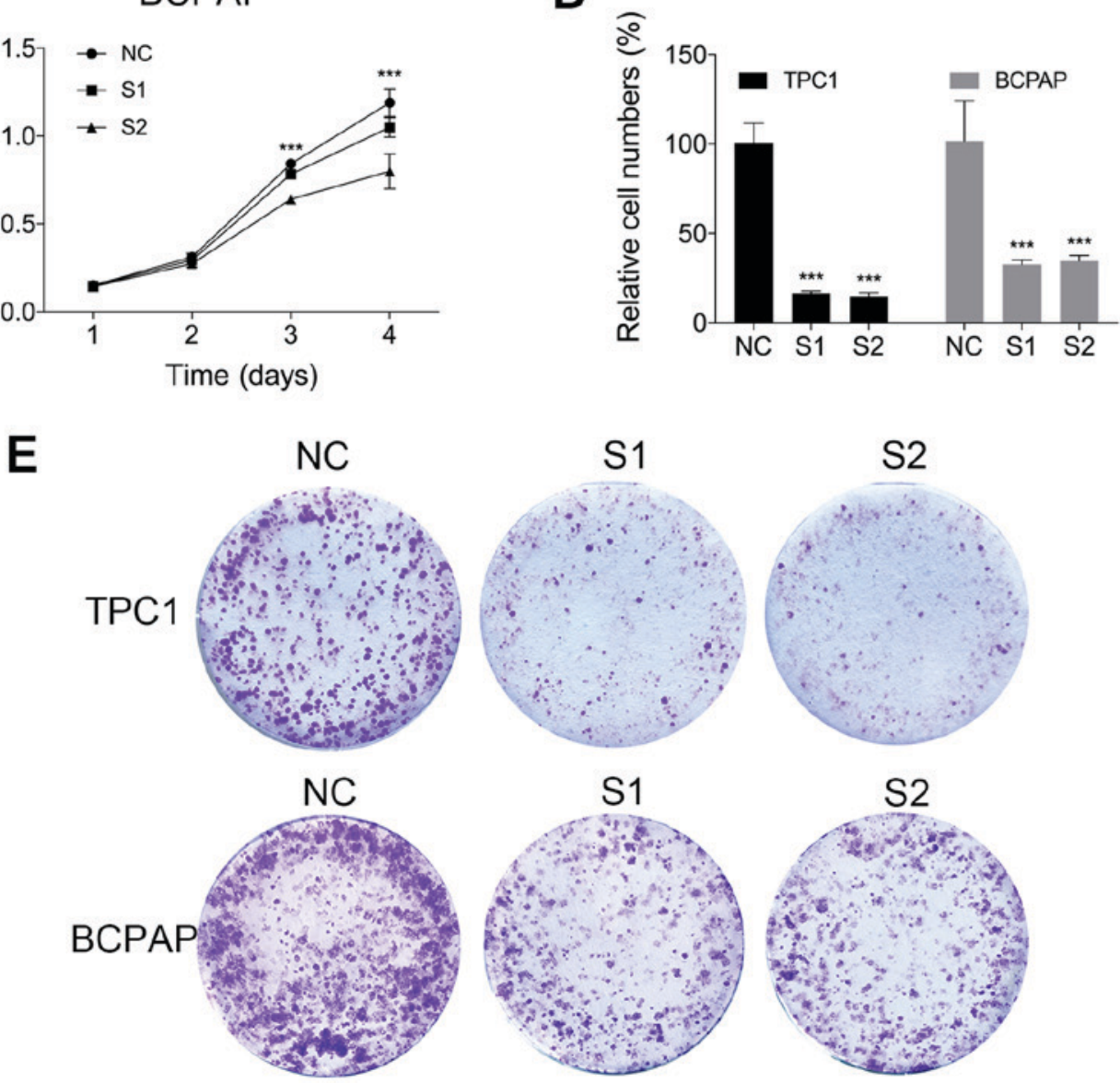

Figure 2. Downregulated expression of CITED1 inhibits cell proliferation in papillary thyroid carcinoma cell lines. (A) Expression level of CITED1 was monitored by reverse transcription-quantitative polymerase chain reaction analysis, and was effectively downregulated in TPC1 and BCPAP cells transfected with siRNA, compared with the NC group. In the cell proliferation assay, proliferation was significantly suppressed in (B) TPC1 and (C) BCPAP cells transfected with siRNA compared with the NC group. (D) Relative quantification of the colony numbers in the (E) colony formation assay, in which TPC1 and BCPAP cells transfected with siRNA and NC group cells were plated in 6-well plates at the appropriate density. Data are presented as the mean \pm standard deviation ranges of expression. ${ }^{* * *} \mathrm{P}<0.001$, compared with the NC group using two-way analysis of variance and a LSD post hoc test. CITED1, Cbp/p300-interacting transactivators with glutamic acid [E] and aspartic acid [D]-rich C-terminal domain 1; siRNA, small interfering RNA; NC, normal control.

gender (OR $0.473,95 \%$ CI $0.284-0.786, \mathrm{P}=0.004)$ and histological type (OR $0.371,95 \%$ CI $0.229-0.600, \mathrm{P}<0.001)$ were positively correlated with increased lymph node metastasis, whereas lymph node metastasis status was not associated with tumor size (OR 2.171 95\% CI 0.962-4.900, P=0.062; Table III). Therefore, upregulated CITED1 increased the risk of lymph node metastasis in patients with PTC.

Downregulated expression of CITED1 inhibits cell proliferation in PTC cell lines. As the CITED1 gene is commonly upregulated in PTC, it was hypothesized that this gene is important in tumorigenesis and progression. Therefore, the present study selected effective siRNA1 and siRNA2 to significantly knock down the expression of CITED1 in the cell lines, and the expression level was evaluated using RT-qPCR analysis (Fig. 2A). Cell proliferation assays and colony formation assays were then performed. The results revealed that the downregulation of CITED1 effectively inhibited thyroid cell line proliferation (Fig. 2B and C, P<0.001) and colony formation (Fig. 2D and E, $\mathrm{P}<0.001)$, compared with the control group. 
A
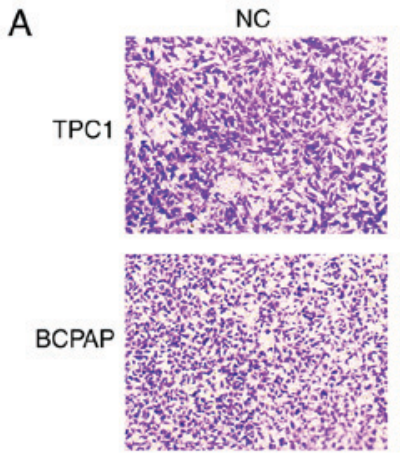

NC

C
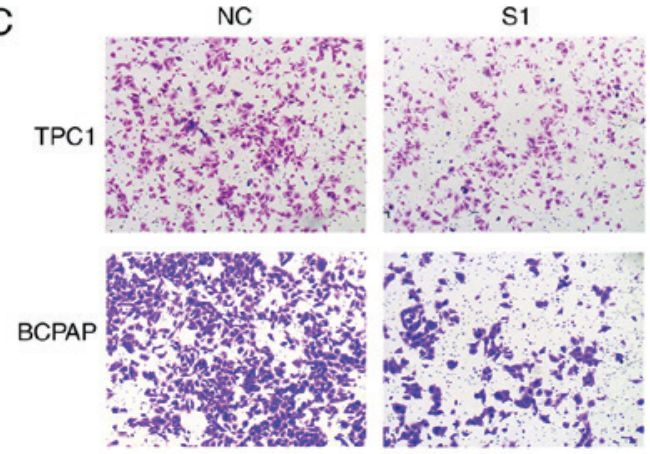

S1
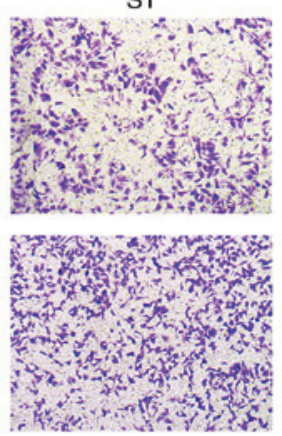

S1
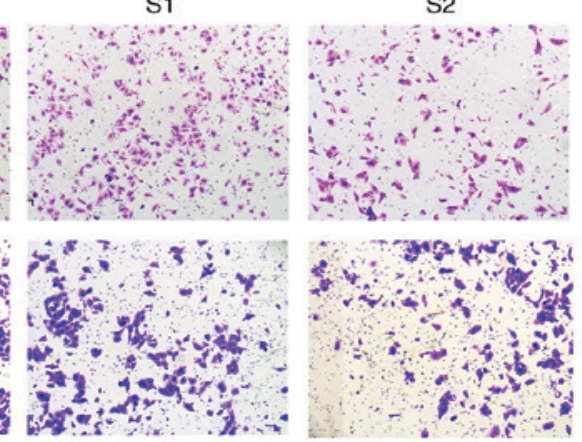

S2
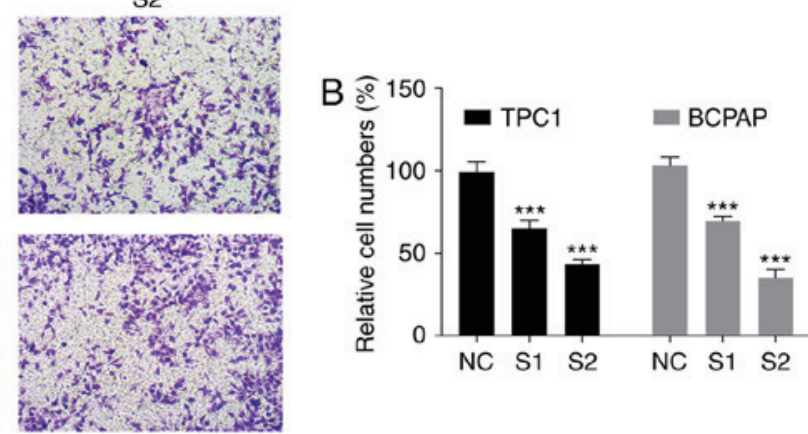

Figure 3. Downregulated of CITED1 inhibits migration and invasion in papillary thyroid carcinoma cell lines. (A) Migration assay (magnification, x10) and (B) Relative quantification of migrating cell number. Migrating cell numbers were lower in the TPC1 and BCPAP cells transfected with siRNA, compared with that in the NC group. (C) Invasion assay (magnification, x10) and (D) relative quantification of invading cell numbers. The invading cell number was lower in cells transfected with siRNA, compared with that in the NC group. Data are presented as the mean \pm standard deviation ranges of expression. ${ }^{* * *} \mathrm{P}<0.001$, compared with the NC group using two-way analysis of variance and an LSD post hoc test. CITED1, Cbp/p300-interacting transactivators with glutamic acid [E] and aspartic acid [D]-rich C-terminal domain 1; siRNA, small interfering RNA; NC, normal control.

Downregulated of CITED1 inhibits migration and invasion in PTC cell lines. As the increased expression level of CITED1 was associated with lymph node metastasis in the clinical feature analysis, the role of CITED1 in PTC was demonstrated using migration and invasion assays. The data revealed that downregulated CITED1 significantly inhibited the PTC cell migration capacity, compared with that in the control group $(\mathrm{P}<0.001$, Fig. 3A and B). The Transwell invasion assays also showed that downregulated CITED1 effectively inhibited the invasion capacity of the PTC cells ( $\mathrm{P}<0.001$, Fig. $3 \mathrm{C}$ and D). The biological function of CITED1 in these experiments was consistent with the results of the clinical feature analysis, revealing that CITED1 is a potential risk factor for metastasis in PTC.

\section{Discussion}

PTC is the most common type of thyroid malignancy, accounting for $>85 \%$ of all cases (21). PTC has a high propensity for lymph node metastasis, with over one-third of patients having clinically detectable lymph node involvement on initial presentation (22). Even in patients with no detectable nodal disease on examination, $\sim 80 \%$ of patients present with micrometastatic lymph node disease on postoperative pathologic examination (23). Several studies have identified that lymph node metastasis can increase the risk of local recurrence, which is a poor prognostic factor (24-26). In order to avoid unnecessary lymph node dissection, it is important to identify a gene associated with PTC as a molecular marker, which can predict the progression and lymph node metastasis status of PTC.

Although thyroid cancer has been investigated in previous decades, $\sim 4 \%$ of PTC cases are without a known oncogenetic driver or epigenetic alterations (27). In the present study, it was found that CITED1 may be a potentially important PTC-associated gene, which was significantly upregulated on analysis of the sequencing dataset. In addition, the expression level of CITED1 was confirmed in TCGA data sets and by relative expression by RT-qPCR analysis.

It is known that CITED1 is important in several types of tumor. In breast cancer, it has been found that expression level of CITED1 parallels that of estrogen receptor (ER) $\alpha$, which resulted in a good outcome. This suggested that potential maintenance of the ER $\alpha$-CITED1 co-regulated signaling pathway in breast tumors can indicate good prognosis (28). However, in other types of tumor, CITED1 is a gene associated with tumorigenesis. The mRNA expression of CITED1 is associated with CXXC finger protein 4 and Kringle containing transmembrane protein 1, which indicated that it as a potential marker in embryonic liver tumors (29). In papillary thyroid cancer, hypomethylation of the $\mathrm{CpGs}$ in the promoter region of CITED1 is associated with a higher mRNA expression of CITED1, indicating that epigenetic regulation is involved in the overexpression of CITED1 (30). The expression of CITED1 has also been identified as an independent risk factor for lymph node metastasis in patents with T3 colorectal cancer, and CITED1 has the potential ability to predict the presence of lymph node 
metastasis in patients with T1 colorectal cancer (31). These studies are consistent with the results of the present study that the CITED1 was a gene associated with PTC and increased the risk of lymph node metastasis in PTC.

In the present study, the mRNA expression level of CITED1 was evaluated by RT-qPCR analysis, which was consistent with the bioinformatics analysis. In addition, logistic regression analysis indicated that a high expression of CITED1 was a risk factor for lymph node metastasis in patients with PTC. In PTC cell lines, it was demonstrated that downregulated CITED1 inhibited cell proliferation and colony formation, and decreased migration and invasion, which was observed using cellular and molecular approaches. These results were consistent with clinicopathological features that showed CITED1 was associated with lymph node metastasis and increased risk of metastasis.

The present study, as with others, had several limitations. First, the function of CITED1 was not verified in vivo. Second, the mechanism of CITED1 in tumorigenesis and metastasis remains to be elucidated and requires further investigation. Finally, the number of patients recruited was limited and additional cases are required to provide more rigorous results.

In conclusion, the present study investigated the association between CITED1 and lymph node metastasis, and the function of CITED1 in vitro. It was found that CITED1 was significantly associated with lymph node metastasis, and that CITED1 resulted in increased tumorigenesis and metastasis. These findings provide a potential diagnostic and therapeutic molecular marker for PTC.

\section{Acknowledgements}

The authors would like to thank Ms.Jizhao Niu (Division of Cardiothoracic Surgery, The First Affiliated Hospital of Wenzhou Medical University) for their support with the study.

\section{Funding}

The present study was funded by the National Natural Science Foundation of China (grant no. 81372380).

\section{Availability of data and materials}

The data sets supporting the conclusions of this article are included in this article. Raw data are available on the main electronic data storage system of the First Affiliated Hospital of Wenzhou Medical University and access is available from the corresponding author on reasonable request.

\section{Ethical approval and consent to participate}

Written informed consent was obtained from each individual participant. Ethical approval for this study was obtained from the Ethics Committee of the First Affiliated Hospital of Wenzhou Medical University.

\section{Consent for publication}

Written informed consent was obtained from each individual participant for the publication of their data.

\section{Authors' contributions}

$\mathrm{AB}$ and FY analyzed the raw data and wrote the original draft. YW and EX investigated and interpreted the data. ZY and JN collected the raw data. OW conceptualized and designed the study and provided supervision. All authors read and approved the final manuscript.

\section{Competing interests}

The authors declare that they have no competing interests.

\section{References}

1. Jemal A, Siegel R, Ward E, Hao Y, Xu J, Murray T and Thun MJ: Cancer statistics, 2008. CA Cancer J Clin 58: 71-96, 2008.

2. Smith RA, Manassaram-Baptiste D, Brooks D, Doroshenk M, Fedewa S, Saslow D, Brawley OW and Wender R: Cancer screening in the United States, 2015: A review of current American cancer society guidelines and current issues in cancer screening. CA Cancer J Clin 65: 30-54, 2015.

3. Cabanillas ME, McFadden DG and Durante C: Thyroid cancer. Lancet 388: 2783-2795, 2016.

4. Cha YJ and Koo JS: Next-generation sequencing in thyroid cancer. J Transl Med 14: 322, 2016.

5. Hunt J: Understanding the genotype of follicular thyroid tumors. Endocr Pathol 16: 311-321, 2005.

6. Wang QX, Chen ED, Cai YF, Li Q, Jin YX, Jin WX, Wang YH, Zheng ZC, Xue L, Wang OC and Zhang XH: A panel of four genes accurately differentiates benign from malignant thyroid nodules. J Exp Clin Cancer Res 35: 169, 2016.

7. Watanabe R, Hayashi Y, Sassa M, Kikumori T, Imai T, Kiuchi T and Murata Y: Possible involvement of BRAFV600E in altered gene expression in papillary thyroid cancer. Endocr J 56: 407-414, 2009.

8. Nikiforova MN and Nikiforov YE: Molecular diagnostics and predictors in thyroid cancer. Thyroid 19: 1351-1361, 2009.

9. Tang KT and Lee CH: BRAF mutation in papillary thyroid carcinoma: Pathogenic role and clinical implications. J Chin Med Assoc 73: 113-128, 2010.

10. Huang Y, Prasad M, Lemon WJ, Hampel H, Wright FA, Kornacker K, LiVolsi V, Frankel W, Kloos RT, Eng C, et al: Gene expression in papillary thyroid carcinoma reveals highly consistent profiles. Proc Natl Acad Sci USA 98: 15044-15049, 2001.

11. Prasad ML, Pellegata NS, Kloos RT, Barbacioru C, Huang Y and de la Chapelle A: CITED1 protein expression suggests Papillary Thyroid Carcinoma in high throughput tissue microarray-based study. Thyroid 14: 169-175, 2004.

12. Shioda T, Fenner MH and Isselbacher KJ: MSG1, a novel melanocyte-specific gene, encodes a nuclear protein and is associated with pigmentation. Proc Natl Acad Sci USA 93: 12298-12303, 1996.

13. Yahata T, Shao W, Endoh H, Hur J, Coser KR, Sun H, Ueda Y, Kato S, Isselbacher KJ, Brown M and Shioda T: Selective coactivation of estrogen-dependent transcription by CITED1 CBP/p300-binding protein. Genes Dev 15: 2598-2612, 2001.

14. Shioda T, Fenner MH and Isselbacher KJ: MSG1 and its related protein MRG1 share a transcription activating domain. Gene 204: 235-241, 1997.

15. Prasad ML, Pellegata NS, Huang Y, Nagaraja HN, de la Chapelle A and Kloos RT: Galectin-3, fibronectin-1, CITED-1, HBME1 and cytokeratin-19 immunohistochemistry is useful for the differential diagnosis of thyroid tumors. Mod Pathol 18: 48-57, 2005.

16. Li H, Ahmed NU, Fenner MH, Ueda M, Isselbacher KJ and Shioda T: Regulation of expression of MSG1 melanocyte-specific nuclear protein in human melanocytes and melanoma cells. Exp Cell Res 242: 478-486, 1998.

17. Sedghizadeh PP, Williams JD, Allen CM and Prasad ML: MSG-1 expression in benign and malignant melanocytic lesions of cutaneous and mucosal epithelium. Med Sci Monit 11: BR189-BR194, 2005.

18. Lovvorn HN III, Boyle S, Shi G, Shyr Y, Wills ML, Perantoni AO and de Caestecker M: Wilms' tumorigenesis is altered by misexpression of the transcriptional co-activator, CITED1. J Pediatr Surg 42: 474-481, 2007. 
19. Schweppe RE, Klopper JP, Korch C, Pugazhenthi U, Benezra M, Knauf JA, Fagin JA, Marlow LA, Copland JA, Smallridge RC and Haugen BR: Deoxyribonucleic acid profiling analysis of 40 human thyroid cancer cell lines reveals cross-contamination resulting in cell line redundancy and misidentification. J Clin Endocrinol Metab 93: 4331-4341, 2008.

20. Livak KJ and Schmittgen TD: Analysis of relative gene expression data using real-time quantitative PCR and the 2(-Delta Delta C(T)) method. Methods 25: 402-408, 2001.

21. Kuo SF, Lin SF, Chao TC, Hsueh C, Lin KJ and Lin JD: Prognosis of multifocal papillary thyroid carcinoma. Int J Endocrinol 2013: 809382, 2013.

22. SanchoJJ,Lennard TW, Paunovic I, Triponez F and Sitges-Serra A Prophylactic central neck disection in papillary thyroid cancer: A consensus report of the European society of endocrine surgeons (ESES). Langenbecks Arch Surg 399: 155-163, 2014.

23. Pereira JA, Jimeno J, Miquel J, Iglesias M, Munné A, Sancho JJ and Sitges-Serra A: Nodal yield, morbidity, and recurrence after central neck dissection for papillary thyroid carcinoma. Surgery 138: 1095-1101, 2005.

24. Machens A, Hinze R, Thomusch O and Dralle H: Pattern of nodal metastasis for primary and reoperative thyroid cancer. World J Surg 26: 22-28, 2002.

25. Zaydfudim V, Feurer ID, Griffin MR and Phay JE: The impact of lymph node involvement on survival in patients with papillary and follicular thyroid carcinoma. Surgery 144: 1070-1078, 2008.

26. Leboulleux S, Rubino C, Baudin E, Caillou B, Hartl DM, Bidart JM, Travagli JP and Schlumberger M: Prognostic factors for persistent or recurrent disease of papillary thyroid carcinoma with neck lymph node metastases and/or tumor extension beyond the thyroid capsule at initial diagnosis. J Clin Endocrinol Metab 90: 5723-5729, 2005.
27. Cancer Genome Atlas Research Network: Integrated genomic characterization of papillary thyroid carcinoma. Cell 159: 676-690, 2014

28. McBryan J, Howlin J, Kenny PA, Shioda T and Martin F: ERalpha-CITED1 co-regulated genes expressed during pubertal mammary gland development: Implications for breast cancer prognosis. Oncogene 26: 6406-6419, 2007.

29. Murphy AJ, de Caestecker C, Pierce J, Boyle SC, Ayers GD, Zhao Z, Libes JM, Correa H, Walter T, Huppert SS, et al: CITED1 expression in liver development and hepatoblastoma. Neoplasia 14: 1153-1163, 2012.

30. Sassa M, Hayashi Y, Watanabe R, Kikumori T, Imai T, Kurebayashi J, Kiuchi T and Murata Y: Aberrant promoter methylation in overexpression of CITED1 in papillary thyroid cancer. Thyroid 21: 511-517, 2011

31. Nasu T, Oku Y, Takifuji K, Hotta T, Yokoyama S, Matsuda K, Tamura K, Ieda J, Yamamoto $\mathrm{N}$, Takemura S, et al: Predicting lymph node metastasis in early colorectal cancer using the CITED1 expression. J Surg Res 185: 136-142, 2013. International (CC BY-NC-ND 4.0) License. 